\title{
Bond Strength of Different Adhesive Systems to Dental Hard Tissues
}

\author{
AR Yazici • Ç Çelik \\ G Özgünaltay • B Dayangaç
}

\section{Clinical Relevance}

Bond strength to dental hard tissues was dependent upon the type of adhesive system used and varied with respect to tooth regions.

\section{SUMMARY}

This study compared the shear bond strengths of different adhesive systems to enamel and dentin of different depths. The adhesive systems used were: Single Bond one-bottle total-etch; AQ Bond one-step self-etching, Clearfil SE Bond two-step self-etching and Tyrian SPE/One-step Plus two-step self-etching.

\footnotetext{
*A Rüya Yazici, DDS, PhD, associate professor, Hacettepe University, Faculty of Dentistry, Department of Conservative Dentistry, Ankara, Turkey

Çigdem Çelik, DDS, PhD, research assistant, Hacettepe University, Faculty of Dentistry, Department of Conservative Dentistry, Ankara, Turkey

Gül Özgünaltay, DDS, PhD, professor, Hacettepe University, Faculty of Dentistry, Department of Conservative Dentistry, Ankara, Turkey

Berrin Dayangaç, DDS, PhD, professor, Hacettepe University, Faculty of Dentistry, Department of Conservative Dentistry, Ankara, Turkey

*Reprint request: 06100, Sihhiye, Ankara, Turkey; e-mail: ruyay@hacettepe.edu.tr

DOI: $10.2341 / 06-49$
}

Eighty extracted non-carious human mandibular molars were mounted in self-curing resin and the occlusal surfaces were ground with a mechanical grinder to obtain flat occlusal enamel surfaces. After applying the adhesive systems, a plastic tube was attached to the enamel surfaces. The tube was filled with a universal hybrid resin composite, which was then polymerized. The specimens were stored in water at $37^{\circ} \mathrm{C}$ for 24 hours. Shear bond testing was carried out using an Instron Universal testing machine with a crosshead speed of $1 \mathrm{~mm} / \mathrm{minute}$. The occlusal enamel of the 80 teeth was removed to determine the bond strengths of the adhesives to superficial dentin. To obtain deep dentin, the same teeth were ground deep towards the pulp, with the remaining dentin thickness approximately $0.7 \mathrm{~mm}$. The adhesives and restorative material were then applied to the prepared dentin surfaces following the methodology described above. For occlusal enamel surfaces, the bond strength of Single Bond was significantly higher than the other adhesives. Single Bond, Clearfil SE Bond and Tyrian SPE/One-step 
Plus performed equally when bonded to superficial dentin; the lowest bond strength was obtained with AQ Bond. On deep dentin, the highest bond strengths were obtained with Clearfil SE Bond.

For each adhesive system, shear bond strength to enamel was statistically higher than it was to either superficial or deep dentin. There were no significant differences between shear bond strengths to superficial versus deep dentin, regardless of adhesive.

\section{INTRODUCTION}

The most currently used adhesive system classification is based on the number of steps necessary for clinical application and on interaction with dental hard tissues. Total-etch adhesive systems, which remove the smear layer with phosphoric acid and combine the functions of primer and adhesive in one bottle, have been widely used. ${ }^{1}$ Although long-term clinical success has been achieved with total-etch systems, ${ }^{2-3}$ the demand for simplified application has increased, resulting in the development of self-etching adhesive systems. The bonding mechanism of self-etching adhesive systems is based on the simultaneous etching and priming of enamel and dentin without rinsing, forming a continuum in the substrate and incorporating smear plugs into the resin tags. ${ }^{4-5} \mathrm{~A}$ self-etch approach involves either a one- or twostep application procedure. Moreover, depending on etching aggressiveness, self-etching adhesives can be subdivided into strong, moderate and mild. ${ }^{6.7}$ The bond strength of self-etching adhesives to dentin was found to be almost equal to total-etch adhesives..$^{8.9}$ However, there is some concern about the bonding effectiveness of self-etching adhesives to enamel. While several studies showed that total-etch adhesives yielded enamel bond strength values superior to self-etching adhesives, ${ }^{10-12}$ others have reported that there was no significant difference in enamel bond strengths between these two types of adhesive systems. ${ }^{13-18}$

The reliability of dentin adhesives is dependent upon the quality of the dentin. Variation in dentin depth can have a significant influence on the bond strength of adhesive systems, as the density and number of tubules play important roles in adhesion..$^{19-21}$ In a study investigating the bond strength of self-etching adhesives to enamel, superficial and deep dentin, no statistically significant differences between adhesive bond strength values were observed for superficial and deep dentin. ${ }^{22}$ On the other hand, in another study, self-etching and onebottle adhesives exhibited significantly lower bond strengths when bonded to deep dentin. ${ }^{23}$

A number of studies have investigated the bonding ability of adhesive systems to either enamel, dentin or both. Although such results are of great value for comparative purposes, in clinical situations, the depth of dentin differs in cavity preparation. Most clinically prepared cavities are complex in design and include not only areas of exposed enamel and superficial dentin, but also deep dentinal areas. Since many different adhesive systems are on the market today, it is desirable to use adhesive systems that produce high, uniform bond strengths to all of these dental hard tissues. As there seems to be few studies related to how these adhesive systems bond to enamel, superficial and deep dentin, the bond strength of adhesives to all these dental hard tissues is a subject in need of investigation. Therefore, the objectives of this study were to: 1) evaluate the shear bond strength of different adhesive systems (Single Bond, a one-bottle total-etch adhesive; AQ Bond, a onestep self-etching adhesive; Clearfil SE Bond, a two-step self-etching adhesive; Tyrian SPE/One-step Plus, a twostep self-etching adhesive) to enamel and dentin of different depths and 2) to determine the difference in bond strengths between these adhesive systems.

\section{METHODS AND MATERIALS}

Eighty extracted non-carious human mandibular molars, which had been stored for less than four weeks in $0.2 \%$ thymol, were selected and cleaned. The teeth were mounted in self-curing resin. The occlusal surfaces were ground with 120-grit abrasive on a water cooled Ecomet grinder (Buehler, Lake Bluff, IL, USA) to obtain a flat enamel surface and subsequently polished for 30 seconds with wet 240-, 400- and 600-grit silicon carbide abrasive paper. The teeth were then randomly assigned to four groups $(n=20)$, and one of the adhesive systems was applied. Four commercially available adhesive systems were examined: a one-bottle totaletch adhesive (Single Bond, 3M ESPE, St Paul, MN, USA), a one-step self-etching adhesive (AQ Bond, Sun Medical, Shiga, Japan) and two different two-step selfetching adhesives (Clearfil SE Bond, Kuraray Co Ltd, Osaka, Japan and Tyrian SPE/One-step Plus, BISCO, Inc, Shaumburg, IL, USA). The adhesives were used according to the manufacturers' instructions. Table 1 lists the composition of these adhesives and instructions for their use.

Following application of the adhesives, a plastic tube ( $3 \mathrm{~mm}$ in diameter and $3 \mathrm{~mm}$ in length) was seated securely against the flattened enamel surface. A universal hybrid resin composite, TPH (Dentsply DeTrey, Kostanz, Germany), was incrementally placed into the tube and polymerized for 40 seconds using a light-curing unit (Hilux, Benlioglu Dental, Ankara, Turkey) with a light intensity above $500 \mathrm{~mW} / \mathrm{cm}^{2}$. The light output of the curing unit was monitored with a light meter (Curing Radiometer Model 100; Demetron Corp, Danbury, CT, USA). 


\begin{tabular}{|c|c|c|}
\hline Adhesive & Composition & Procedure \\
\hline Single Bond & $\begin{array}{l}\text { Etchant: } 35 \% \text { phosphoric acid } \\
\text { Adhesive: HEMA, } \\
\text { dimethacrylate, Bis-GMA, } \\
\text { ethanol, water }\end{array}$ & $\begin{array}{l}\text { Apply acid for } 15 \text { seconds, rinse and dry } \\
\text { gently. } \\
\text { Apply two coats, dry gently, } 10 \text { seconds } \\
\text { light cure. }\end{array}$ \\
\hline AQ Bond & $\begin{array}{l}\text { Adhesive: 4-META, UDMA, } \\
\text { acetone, water } \\
\text { AQ Sponge: Sodium p-toluensulfinate }\end{array}$ & $\begin{array}{l}\text { Apply three coats using a saturated } A Q \\
\text { sponge, dry gently, } 10 \text { seconds light cure. }\end{array}$ \\
\hline Clearfil SE Bond & $\begin{array}{l}\text { Primer: HEMA, MDP, hydrophilic } \\
\text { dimethacrylate, water } \\
\text { Adhesive: MDP, Bis-GMA, HEMA, } \\
\text { hydrophilic dimethacrylate, microfiller }\end{array}$ & $\begin{array}{l}\text { Apply SE-Primer for } 20 \text { seconds, dry gently, } \\
\text { apply SE-Bond, dry gently, } 10 \text { seconds light } \\
\text { cure. }\end{array}$ \\
\hline $\begin{array}{l}\text { Tyrian SPE/One- } \\
\text { Step Plus }\end{array}$ & $\begin{array}{l}\text { Primer A: Thymol blue, ethanol, water } \\
\text { Primer B: AMPS, bisMEP, TPO, ethanol } \\
\text { One Step Plus: Bis-GMA, BPDM, HEMA, } \\
\text { CQ p-dimethylaminobenzic acid(co- } \\
\text { initiator), acetone, } 8.5 \% \text { glass fillers }\end{array}$ & $\begin{array}{l}\text { Apply mixture of Primer } A \text { and } B \text { with } \\
\text { continuous rubbing for } 10 \text { seconds. Then } \\
\text { apply two coats of the bonding resin One- } \\
\text { Step Plus, dry gently, } 10 \text { seconds light cure. }\end{array}$ \\
\hline \multicolumn{3}{|c|}{$\begin{array}{l}\text { 4-META: 4-metacryloxyethyl trimellitate anhydride; UDMA: urethane dimethacrylate; MDP: 10-methacryloyloxydecyl dihydrogen phosphate; } \\
\text { HEMA: 2-hydroxyethylmethacrylate; Bis-GMA: (1-methylethliede)bis[4, 1-phenyleneoxy(2-hydroxy-3,1propanediyl)]bismethacrylate; } \\
\text { AMPS: 2-acryloamido-2-methylpropane-sulfonic acid; BisMEP: Bis(2-(methacryloyloxy)ethyly) phosphate; BPDM: biphenyl dimethacrylate; } \\
\text { TPO: 2.4.6-[trimethylbenzoyldiphenylphosphine] oxide; CQ: camphorquinone }\end{array}$} \\
\hline
\end{tabular}

The specimens were stored in water at $37^{\circ} \mathrm{C}$ for 24 hours. Shear bond strengths were determined using a Universal Testing Machine (Model 4444, Instron Corporation, Canton, MA, USA) at a crosshead speed of $1 \mathrm{~mm} /$ minute. Shear bond strengths in MPa were calculated by dividing the maximum force that induced failure by the bonded area.

After measuring bond strength values of the adhesive systems to enamel, the occlusal enamel of the same teeth was removed with a water-cooled slow-speed diamond saw (Isomet, Buehler) to determine the bond strengths of the adhesives to superficial dentin. After exposing the superficial dentin, flat dentin surfaces were polished with 600-grit silicon carbide paper under running water to create a uniform surface and smear layer. The adhesives and restorative material were then applied to the prepared dentin surfaces following the methodology described above.

To reach deep dentin, the same teeth were deeply ground towards the pulp with 120 -grit abrasive on a water-cooled Ecomet grinder (Buehler), with the remaining dentin thickness approximately $0.7 \mathrm{~mm}$ from the exposed dentin surfaces. The remaining dentin thickness was verified with periapical radiographs using double-packet Kodak Ektaspeed dental X-ray film (Eastman Kodak Co, Rochester, NY, USA). These radiographs were taken with a Planmeca Prostyle
Intra (Helsinki, Finland) intraoral radiography unit that was operated at $63 \mathrm{kVp}, 8 \mathrm{~mA}$. The adhesives and restorative material were then applied to the prepared deep dentin surfaces following the methodology previously described.

Bond strength data were statistically analyzed using two-way ANOVA to determine the effects of different adhesive systems on different dental hard tissues and the interactions between these two factors on the shear bond strengths. Differences between the groups were analyzed using one-way ANOVA/Tukey HSD post-hoc test $(p<0.05)$.

\section{RESULTS}

The mean shear bond strength values and standard deviations in MPa are shown in Table 2.

Two-way ANOVA revealed that the bond strength results were significantly influenced by the different adhesive systems $(\mathrm{F}=18.73 ; p=0.00)$ and dental hard tissues $(\mathrm{F}=51.8 ; p=0.00)$. The interaction of these factors was also statistically significant $(\mathrm{F}=6.8 ; p=0.00)$. 
Results of the comparisons of adhesive system vs adhesive system and dental hard tissues vs dental hard tissues are shown in Tables 3 and 4, respectively.

Significant differences in bond strengths to enamel were found between the adhesive systems $(p=0.00)$. The bond strength of Single Bond one-bottle total-etch adhesive to enamel was statistically higher than other tested adhesives.

The one-step self-etching adhesive AQ Bond showed significantly lower bond strength to superficial dentin than did the two-step self-etching adhesives Clearfil SE Bond, Tyrian SPE/One-step Plus and Single Bond one bottle total-etch adhesive. There were no statistical differences between the two two-step self-etching adhesives and the one-bottle total-etch adhesive bond strengths to superficial dentin $(p<0.05)$.

For deep dentin, Clearfil SE Bond exhibited significantly higher bond strengths than the other tested adhesives.

For each adhesive system, shear bond strength to enamel was statistically higher than to either superficial or deep dentin $(p<0.05)$.

There were no significant differences between shear bond strengths to superficial versus deep dentin, regardless of adhesive $(p>0.05)$.

\section{DISCUSSION}

Enamel adhesion by means of acid etching has become an accepted technique in restorative dentistry. Phosphoric acid conditioning of dental enamel causes preferential dissolution of interprismatic enamel, allowing micro-mechanical retention by adhesive resins. While traditionally $30 \%-40 \%$ phosphoric acids have generally been used in total-etch adhesive systems, ${ }^{7}$ self-etching adhesives are composed of acidic monomers rather than phosphoric acid. ${ }^{24}$ The mild aggressiveness of these acidic monomers could result in minor modifications and less enamel loss, which, in turn, could affect resin adaptation..$^{25}$ In a morphological study evaluating the surface of etched enamel, Perdigão and others ${ }^{26}$ reported that the application of self-etching adhesive primer did not result in as deep an enamel etching pattern as did the application of phosphoric acid.
These results are supported by enamel bond strength studies in which total-etch adhesives were proven to be superior to self-etching adhesives. ${ }^{10-12}$ De Munck and others ${ }^{10}$ reported that one-step self-etching adhesives produced lower bond strengths than two-step self-etching adhesives. In the current study, although two-step self-etching adhesives produced higher bond strengths, they did not significantly differ from one-step self-etching adhesive.

When the current study compared the dentin bonding effectiveness of self-etching adhesives to total-etch adhesives, it was found that AQ Bond one-step selfetching adhesive produced significantly lower bond strengths to superficial dentin. The other two-step selfetching adhesives were comparable to total-etch adhesive. The reason for the low bond strength values obtained by $\mathrm{AQ}$ Bond could be its relatively higher $\mathrm{pH}$ (2.5), which might have been incapable of etching superficial dentin. Another reason could be related to its hydrophilic properties. It is known that one-step self-etching adhesives are more hydrophilic than twostep self-etching adhesives ${ }^{7}$ and they attract more water. As it is difficult to evaporate water from these adhesives, water will rapidly diffuse back from the bonded dentin into the adhesive resin and, subsequently, a lower mechanical strength results. ${ }^{28}$ Recent reports indicate that one-step self-etching adhesives do not perform well in bond strength measurements..$^{10,29-30}$

\begin{tabular}{|l|l|c|c|}
\hline $\begin{array}{l}\text { Table 3: p-values for Comparison: Adhesive vs Adhesive for Each } \\
\text { Dental Hard Tissue (the underlined p-values are <0.05 } \\
\text { and indicate significant difference) }\end{array}$ \\
\hline Enamel & CSE & TSPE & SB \\
\hline AQ & 0.368 & 0.923 & $\underline{0.000}$ \\
\hline CSE & & 0.748 & $\underline{0.001}$ \\
\hline TSPE & & & $\underline{0.000}$ \\
\hline Superficial Dentin & & & \\
\hline AQ & $\underline{0.002}$ & $\underline{0.044}$ & $\underline{0.012}$ \\
\hline CSE & & 0.365 & 0.924 \\
\hline TSPE & & & 0.743 \\
\hline Deep Dentin & & & 0.138 \\
\hline AQ & $\underline{0.000}$ & 0.637 & $\underline{0.012}$ \\
\hline CSE & & $\underline{0.000}$ & 0.754 \\
\hline TSPE & & & \\
\hline
\end{tabular}

While self-etching adhesives show shallow etching patterns, in most studies, their bond strengths to enamel were found to be similar to totaletch adhesive systems..$^{13-18}$ In another study comparing self-etching adhesives bond strength to enamel, only Clearfil SE Bond achieved high composite-to-enamel bond strength, which was similar to the total-etch bonding systems. $^{27}$ 
The authors of the current study found that, for deep dentin, Clearfil SE Bond showed statistically higher bond strengths than the other adhesive systems tested. This might be attributable to the two hydroxyl groups in the MDP (10-methacryloyloxydecyl dihydrogen phosphate) molecule, which chelates calcium. ${ }^{31-32}$ Moreover, hydophilic 10-MDP monomer improves wetting of the moist tooth surface. ${ }^{31-33}$ Miyazaki and others ${ }^{34}$ reported that a $10 \%$ filler content in adhesives was necessary to increase bond strength. The presence of fillers may produce a sufficiently thick resin film that stabilizes the hybrid layer and provides an elastic buffer zone that compensates for shrinkage stress during polymerization. ${ }^{8}$ Also mentioned is the effect of filled adhesive being more evident on deep dentin. ${ }^{35-36}$ Clearfil SE Bond is a highly filled adhesive, which might explain its higher bond strength values.

It might be expected that bond strengths to deep dentin would be reduced, because the water content of deep dentin is greater than superficial dentin due to the greater diameter and number of tubules per unit area ${ }^{37-38}$ Tay and others ${ }^{39}$ reported that the higher water content in deep dentin might dilute the organic solvents of some adhesive systems, causing monomers to leave the soluble phase and form resin globules in water. Recent adhesive systems have improved their bonding ability to deep dentin, developing a circumferential hybrid layer that anchors the tag to the adjacent intertubular dentin. ${ }^{40}$

In the current study, depth of dentin appeared to have only a small affect on bond strength. Although the bond strength value of deep dentin was lower than superficial dentin, no statistically significant difference was observed. Burrow and others ${ }^{20}$ also reported that dentin depth had no influence on bond strength. They pointed out the importance of the quality of the resin-impregnated layer to obtaining high bond strengths.

Toledano and others ${ }^{8}$ investigated the bond strength to superficial and deep dentin of five adhesive systems. They found that Single Bond and Clearfil SE Bond performed equally when bonded to superficial dentin; they also showed similar bond strength to both dentin depths. Similar to the findings of this study, for deep dentin, Sattabanasuk and others ${ }^{23}$ found that one-bottle adhesive systems produced significantly lower values than Clearfil SE Bond.

In this study, statistically higher bond strengths were attained with the Clearfil SE Bond system on deep dentin. Pereira and others ${ }^{41}$ reported low bond strength of one-bottle total-etch adhesives to dentin over the pulpal horn region. They also mentioned that water perfusion occurs by removing the smear layer during etching and that rinsing might affect bond strength, even without pulpal pressure. In the current study, when Single Bond was used, residual water, which was left behind after the etching and rinsing steps, might have negatively affected bond strength values.

In a study that evaluated microtensile bond strengths of self-etching adhesives to dentin, Kenshima and oth$\mathrm{ers}^{42}$ found that Tyrian SPE showed the lowest bond strength. They reported that its solvent content is higher than other self-etching adhesives, so that it can promote complete ionization of the acidic monomers. They attributed the comparably lower bond strength value of Tyrian SPE to the higher acetone content of One-Step Plus, which is placed over the self-priming solution. Cho and Dickens ${ }^{43}$ investigated the varying acetone content of different single solution dentin bonding agents and their effects on microtensile bond strength of resin composites and found that lower acetone concentration improved the integrity of the adhesive interface. In this study, Tyrian SPE, which was the most acidic self-etching adhesive tested, provided lower bond strength values than Clearfil SE Bond.

Dentin is known to be a less favorable substrate than enamel for resin bonding due to its high organic content, the presence of fluid and the odontoblastic process in dentin tubules, and the presence of a smear layer on prepared surfaces. ${ }^{44}$ This was confirmed in the current study for all the adhesive systems that demonstrated higher bond strength values for enamel.

The majority of published bond strength tests are performed using enamel or dentin extracted from human and bovine teeth; only a few studies are available that evaluate the shear bond strength of these teeth simulating dentin tubule fluid flow. The authors speculate that these bond strength values would change in vital teeth. Therefore, long-term clinical trials are needed to evaluate the clinical relevance of these in vitro results.

\section{CONCLUSIONS}

Within the limitations of this in vitro study, bond strengths were found to be dependent upon the type of adhesive system used, and they varied with respect to tooth regions.

While enamel bond strengths were greater than dentin for all the adhesive systems tested, no significant difference was observed between superficial and deep dentin bond strengths.

The enamel bonding of the Single Bond one-bottle total-etch adhesive system was significantly greater than the self-etching adhesive systems. One-bottle total-etch and self-etching adhesive systems displayed significantly different bond strengths at both dentinal depths.

\section{Acknowledgement}

The authors thank Erdem Karabulut for his help with the statistical analysis of the data. 
(Received 28 March 2006)

\section{References}

1. Swift EJ Jr, Perdigão J \& Heymann HO (1998) Enamel bond strengths of "one-bottle" adhesives Pediatric Dentistry 20(4) 259-262.

2. Aw TC, Lepe X, Johnson GH \& Mancl LA (2005) A three-year clinical evaluation of two-bottle versus one-bottle dentin adhesives Journal of the American Dental Association 136(3) 311-322.

3. Swift EJ Jr, Perdigão J, Wilder AD Jr, Heymann HO, Sturdevant JR \& Bayne SC (2001) Clinical evaluation of two one-bottle dentin adhesives at three years Journal of the American Dental Association 132(8) 1117-1123.

4. Watanabe I, Nakabayashi N \& Pashley DH (1994) Bonding to ground dentin by a phenyl-P self-etching primer Journal of Dental Research 73(6) 1212-1220.

5. Gordan VV, Vargas MA, Cobb DS \& Denehy GE (1997) Evaluation of adhesive systems using acidic primers American Journal of Dentistry 10(5) 219-223.

6. Pashley DH \& Tay FR (2001) Aggressiveness of contemporary self-etching adhesives Part II: Etching effects on unground enamel Dental Materials 17(5) 430-444.

7. Van Meerbeek B, De Munck J, Yoshida Y, Inoue S, Vargas M, Vijay P, Van Landuyt K, Lambrechts P \& Vanherle G (2003) Buonocore Memorial Lecture. Adhesion to enamel and dentin: Current status and future challenges Operative Dentistry 28(3) 215-235.

8. Toledano M, Osorio R, Ceballos L, Fuentes MV, Fernandes CA, Tay FR \& Carvalho RM (2003) Microtensile bond strength of several adhesive systems to different dentin depths American Journal of Dentistry 16(5) 292-298.

9. Munck De J, Vargas M, Iracki J, Van Landuyt K, Poitevin A, Lambrechts P \& Van Meerbeek B (2005) One-day bonding effectiveness of new self-etch adhesives to bur-cut enamel and dentin Operative Dentistry 30(1) 39-49.

10. De Munck J, Van Meerbeek B, Satoshi I, Vargas M, Yoshida Y, Armstrong S, Lambrechts P \& Vanherle G (2003) Microtensile bond strength of one- and two-step self-etch adhesives to bur-cut enamel and dentin American Journal of Dentistry 16(6) 414-420.

11. Goracci C, Sadek FT, Monticelli F, Cardoso PE \& Ferrari M (2004) Microtensile bond strength of self-etching adhesives to enamel and dentin Journal of Adhesive Dentistry 6(4) 313318.

12. Perdigão J, Gomes G, Duarte S Jr \& Lopes MM (2005) Enamel bond strengths of pairs of adhesives from the same manufacturer Operative Dentistry 30(4) 492-499.

13. Hannig M, Reinhardt KJ \& Bott B (1999) Self-etching primer vs phosphoric acid: An alternative concept for composite-toenamel bonding Operative Dentistry 24(3) 172-180.

14. Kanemura N, Sano H \& Tagami J (1999) Tensile bond strength to and SEM evaluation of ground and intact enamel surfaces Journal of Dentistry 27(7) 523-530.

15. Shimada Y, Senawongse P, Harnirattisai C, Burrow MF, Nakaoki Y \& Tagami J (2002) Bond strength of two adhesive systems to primary and permanent enamel Operative Dentistry 27(4) 403-409.
16. Miyazaki M, Sato M \& Onose H (2000) Durability of enamel bond strength of simplified bonding systems Operative Dentistry 25(2) 75-80.

17. Pilecki P, Stone DG, Sherriff M \& Watson TF (2005) Microtensile bond strengths to enamel of self-etching and one bottle adhesive systems Journal of Oral Rehabilitation 32(7) 531-540.

18. Kelsey WP $3^{\text {rd }}$, Latta MA, Vargas MA, Carroll LR \& Armstrong SR (2005) Microtensile bond strength of total-etch and self-etch adhesives to the enamel walls of Class V cavities American Journal of Dentistry 18(1) 37-40.

19. Tagami J, Tao L \& Pashley DH (1990) Correlation among dentin depth, permeability and bond strength of adhesive resins Dental Materials 6(1) 45-50.

20. Burrow MF, Takakura H, Nakajima M, Inai N, Tagami J \& Takatsu T (1994) The influence of age and depth of dentin on bonding Dental Materials 10(4) 241-246.

21. Prati C \& Pashley DH (1992) Dentin wetness, permeability and thickness and bond strength of adhesive systems American Journal of Dentistry 5(1) 33-38.

22. Kaaden C, Powers JM, Friedl KH \& Schmalz G (2002) Bond strength of self-etching adhesives to dental hard tissues Clinical Oral Investigations 6(3) 155-160.

23. Sattabanasuk V, Shimada Y \& Tagami J (2004) The bond of resin to different dentin surface characteristics Operative Dentistry 29(3) 333-341.

24. Kugel G \& Ferrari M (2000) The science of bonding: From first to sixth generation Journal of the American Dental Association 131(Supplement) 20S-25S.

25. Breschi L, Gobbi P, Falconi M, Mazzotti G, Prati C \& Perdigão J (2003) Ultra-morphology of self-etching adhesives on ground enamel: A high resolution SEM study American Journal of Dentistry 16 Spec No: 57A-62A.

26. Perdigão J, Lopes L, Lambrechts P, Leitao J, Van Meerbeek B \& Vanherle G (1997) Effects of a self-etching primer on enamel shear bond strengths and SEM morphology American Journal of Dentistry 10(3) 141-146.

27. Lopes GC, Marson FC, Vieira LC, Caldeira AM \& Baratieri LN (2004) Composite bond strength to enamel with self-etching primers Operative Dentistry 29(4) 424-429.

28. Bastioli C, Romano G \& Migliaresi C (1990) Water sorption and mechanical properties of dental composites Biomaterials 11(3) 219-223.

29. Haller B (2000) Recent developments in dentin bonding American Journal of Dentistry 13(1) 44-50.

30. Cardoso PE, Placido E, Francci CE \& Perdigão J (1999) Microleakage of Class $\mathrm{V}$ resin-based composite restorations using five simplified adhesive systems American Journal of Dentistry 12(6) 291-294.

31. Hayakawa T, Kikutake K \& Nemoto K (1998) Influence of self-etching primer treatment on the adhesion of resin composite to polished dentin and enamel Dental Materials 14(2) 99-105.

32. Perdigão J, Eriksson S, Rosa BT, Lopes M \& Gomes G (2001) Effect of calcium removal on dentin bond strengths Quintessence International 32(2) 142-146. 
33. Van Meerbeek B, Peumans M, Verschueren M, Gladys S, Braem M, Lambrechts P \& Vanherle G (1994) Clinical status of ten adhesive systems Journal of Dental Research 73(11) 1690-1702.

34. Miyazaki M, Ando S, Hinoura K, Onose H \& Moore BK (1995) Influence of filler addition to bonding agents on shear bond strength to bovine dentin Dental Materials 11(4) 234-238.

35. Marshall GW Jr, Marshall SJ, Kinney JH \& Balooch M (1997) The dentin substrate: Structure and properties related to bonding Journal of Dentistry 25(6) 441-458.

36. Yoshiyama M, Sano H, Ebisu S, Tagami J, Ciucchi B, Carvalho RM, Johnson MH \& Pashley DH (1996) Regional strength of bonding agents to cervical sclerotic root dentin Journal of Dental Research 75(6) 1404-1413.

37. Suzuki T \& Finger WJ (1988) Dentin adhesives: Site of dentin vs bonding of composite resins Dental Materials 4(6) 379-383.

38. Olsson S, Oilo G \& Adamczak E (1993) The structure of dentin surfaces exposed of bond strength measurements Scandinavian Journal of Dental Research 101(3) 180-184.

39. Tay FR, Gwinnett JA \& Wei SH (1998) Relation between water content in acetone/alcohol based primer and interfacial ultrastructure Journal of Dentistry 26(2) 147-156.
40. Pashley DH, Ciucchi B, Sano H, Carvalho RM \& Russell CM (1995) Bond strength versus dentin structure: A modeling approach Archives of Oral Biology 40(12) 1109-1118.

41. Pereira PR, Okuda M, Sano H, Yoshikawa T, Burrow MF \& Tagami J (1999) Effect of intrinsic wetness and regional difference on dentin bond strength Dental Materials 15(1) $46-53$.

42. Kenshima S, Reis A, Uceda-Gomez N, Tancredo L de L, Filho LE, Nogueira FN \& Loguercio AD (2005) Effect of smear layer thickness and $\mathrm{pH}$ of self-etching adhesive systems on the bond strength and gap formation to dentin Journal of Adhesive Dentistry 7(2) 117-126.

43. Cho BH \& Dickens SH (2004) Effects of the acetone content of single solution dentin bonding agents on the adhesive agents on the adhesive layer thickness and the microtensile bond strength Dental Materials 20(2) 107-115.

44. Leirskar J, Oilo G \& Nordbo H (1998) In vitro shear bond strength of two resin composites to dentin with five different dentin adhesives Quintessence International 29(12) 787-792. 


\section{Announcements

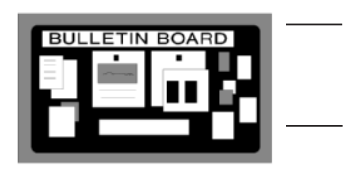

Two half-day essay sessions, social activities, plus clinical demonstrations at the Pearl Harbor Naval Dental Clinic.

For details and information, contact:

\author{
Dr Ronald K Harris \\ Meeting Coordinator \\ 256 Sand Brook Drive \\ Noblesville, IN 460602 \\ Phone: (317) 867-0414 \\ Fax: (317) 867-3011 \\ E-mail: pipedoc@verizon.net
}

\title{
Tucker Institute Course 2007
}

A clinical course in conservative gold castings, mentored by Dr Richard V Tucker, will be held June 18-22, 2007 at the University of Washington Dental School. For course information, contact Dr Dennis Miya, (206) 244-1618 or at dmichi@aol.com.

\section{Faculty Positions}

\section{Riyadh College of Dentistry and Pharmacy \\ Riyadh \\ Kingdom of Saudi Arabia}

Riyadh College of Dentistry and Pharmacy, a private higher education college, seeks full-time/short-time faculty with DDS/DMD, post-doctoral training and assistant/associate/full professors in Operative Dentistry.

- Attractive salary package.

- Annual 30 days paid vacation.

- Roundtrip airline ticket up to four family members.

- Housing/furniture allowance.

- Medical insurance.

- For short time (1-3 months).

Send resumes to: Jobs@riyadh.edu.sa or fax at 009661-2486250.

Tel: 00699-1-2481222 PO Box 84891, Riyadh, 11681, Kingdom of Saudi Arabia; website: www.riyadh.edu.sa.

\section{Operative Dentistry Home Page}

We hope all our readers will take advantage of the information available by accessing our Internet home page. Our address is: http://www.jopdent.org/

The home page contains a buttons that, hopefully, will lead you to answers to any questions you may have related to Operative Dentistry. These are:

Journal: leads to information on the Editorial Staff and Editorial Board; a complete index of journal volumes; a compilation of direct gold references; highlights of the current issue and a detailed look at published Editorials.

Subscribe: leads to complete information on subscription rates; purchasing back issues, reprints, and bound volumes; and subscription and change of address forms.

Affiliates: provides links to the American Academy of Gold Foil Operators, the Academy of Operative Dentistry, RV Tucker Society, the AADS-Operative Section, and our Corporate Sponsors. In addition, membership applications for the journal's parent academies are available for downloading.

News: announcements of interest to our readers, including meeting information, advertised faculty positions, and upcoming $\mathrm{CE}$ courses.

Authors: complete instructions for contributors to the journal.

Reviewers: Link for our Editorial Board to submit manuscript reviews electronically.

\section{Correction}

In Operative Dentistry 32-2 166-172, Bond Strength of Different Adhesive Systems to Dental Hard Tissues, AR Yazici, Ç Çelik, G Özgünaltay \& B Dayangaç, an error was inadvertently made. In the fifth column of Table 2 on pg 168, the bond strength value of Single Bond (SB) one-bottle total etch adhesive to deep dentin was written as 2.9; whereas, it should have been listed as 12.9 . 